Filo. y Lingüí. 10(2): 97-99, 1984.

\title{
ESTRUCTURA DEL CUENTO FANTASTICO EN JORGE LUIS BORGES
}

\author{
Manuel Arce Arenales
}

Desde que apareció la conciencia de un género literario Ilamado "cuento", se inició la consecuente discusión para determinar su estructura esencial. El cuento clásico de Maupassant o Poe admitía una reducción más o menos clara y precisa. Sin embargo, la cuestión se ha ido enredando cada vez más, hasta llegar a una especie de límite de complejidad en la literatura hispanoamericana. Casi podría decirse que un esquema explicativo que lograre abarcar el cuento hispanoamericano abarcaría por definición cualquier otra producción de ese género.

Entre los narradores de Hispanoamérica, Borges destaca en este contexto, no solamente por la difusión y calidad de su producción: sus cuentos permiten adivinar casi siempre una estructura perfecta, pero que se intuye distinta de las estructuras tradicionales. Estudiar la estructura borgiana es dilucidar uno de los límites del paradigma.

En general, estructuralmente las ficciones de Borges responden al siguiente lineamiento: un conjunto de elementos narrativos (personajes, complejos actanciales, acontecimientos, ambientes) que se utiliza para construir la imagen de una idea abstracta. En otras palabras, estos elementos no son sino pretextos para presentar una idea que de otra manera utilizaría el discurso técnico de la filosofía o una larga digresión especulativa en un ensayo. Expresada así, la idea podría parecer inconexa o incluso banal y, por supuesto, perdería casi por completo su valor estético. Esta última virtud, suprema en la narrativa borgiana, se manifiesta no solo en virtud de la economía de recursos empleados para expresar la idea: en sí la misma forma llega a constituir parte de esta idea. La estructura del cuento, pues, es parte integral de la imagen total.

En Tlön, Uqbar, Orbis Tertius, por ejemplo, Bioy Casares, el narrador, la ambientación (la precisión) en la calle Gaona, la propia AngloAmerican Cyclopaedia, no son sino justificaciones de verosimilitud para una idea fantástica: la de un universo en donde el lenguaje sustituye la realidad objetiva. La estructura narrativa forma parte intrínseca de esta noción al crear un nicho verosímil en la realidad para esta ficción: toda la forma del cuento puede resumirse en un prolijo amontonamiento de citas o referencias a la realidad que incluyen o rozan una realidad lingüistica encarnada en la First Encyclopaedia of Tlön. Vol. XI. Hlaer to Jangr. Así, Silas Haslam puede o no ser real, sabemos que Alfonso Reyes sí lo es: en todo caso, ambos son totalmente verosímiles. Irónicamente, parece más verosímil el primero que el segundo: "La biografía enumeraba cuatro volúmenes que no hemos encontrado hasta ahora, aunque el tercero -Silas Haslam: History of the land called Ugbar, 1874- figura en los catálogos de librería de Bernard Quaritch" (1); "Alfonso Reyes, harto de esas fatigas subalternas de índole policial, propone que entre todos acometamos la obra de reconstruir los muchos y macizos tomos que faltan: «ex unque leonem $\gg(2)$.

Las sorprendentes características del universo de Tlön derivan todas de suponer que la realidad es su representación lingü ística: la psicología como disciplina única, la concepción del cosmos como una serie de procesos mentales que no se desenvuelven en el espacio sino en el tiempo, un. idealismo total que invalida la ciencia, la subordinación de la filosofía a la literatura. En este mundo, es lógico que el materialismo sea una paradoja, pues significa invertir la reducción fundamental de lo real al lenguaje.

El idealismo literario de Borges tiene dos manifestaciones fundadas sobre una misma aprehensión formalista de la realidad; ésta se percibe esencialmente como un orden determinado $y$, por tanto, es permisible imaginarla determinable. Por supuesto, el orden por excelencia para Borges es ese modelo de la realidad que cuesta tanto diferenciar de ella: el lenguaje. Así, de los ocho cuentos en El jardín de senderos que se bifurcan, cinco se ocupan de la identidad lenguaje/realidad, manifestada mediante esa hierofanía antonomástica: la palabra escrita. Otros dos exploran la posibilidad de órdenes alternos directos oníricos 
en un caso, social en el otro. La última narración combina ambas vertientes utilizando la variable borgiana por excelencia: el tiempo.

De hecho, al abstraer las ideas que definen cada cuento, la clasificación por pertenencia a cada una de las dos categorías surge espontáneamente, como se ve a continuación:

\section{L1) TLON' UQBAR, ORBIS TERTIUS}

- En alguna parte del universo existe un lugar en donde el lenguaje es la realidad objetiva.

L2) EL ACERCAMIENTO A ALMOTASIM

Un libro ficticio expone una idea frecuente en

la literatura mística: el bien como encarnación que se irradia ignotamente.

L3) PIERRE MENARD, AUTOR DEL QUIJOTE

Una realización absurdamente trivial debe su caracter monstruosamente asombroso a esa misma trivialidad que implica, en un sentido al menos, una exacta duplicación de la realidad.

L4) EXAMEN DE LA OBRA DE HERBERT QUAIN

- Un ficticio autor de libros fantásticos (en donde se exploran la regresión y el involucramiento directo del lector), incluye en uno de estos libros el germen de LAS RUINAS CIRCULARES. L5) LA BIBLIOTECA DE BABEL

- Equivalencia entre verdad y lenguaje, entre realidad y conocimiento.

\section{R1) LAS RUINAS CIRCULARES}

- La construcción de la realidad mediante el sueño nos Ileva a la siguiente equivalencia: afirmar la esencia onírica de la realidad equivale a negar la realidad de la muerte, lo que a su vez afirma la realidad del sueño.

\section{R2) LA BIBLIOTECA DE BABEL}

- La realidad es una construcción social: Io prueba un regimen estructurado sobre un gobierno no de ley sino de azar.

\section{LR1) EL JARDIN DE SENDEROS QUE SE BIFURCAN}

- La multiplicidad de lo real niega una sola realidad, y se manifiesta como un laberinto en el tiempo, encarnado en un libro.

Borges siempre subvierte la realidad: varían únicamente sus formas de hacerlo. En LAS RUINAS CIRCULARES, la subversión directa se lleva a cabo mediante un orden narrativo que recuerda las técnicas del cuento clásico. La subversión indirecta es más frecuente: el subterfugio más común empleado para llevarla a cabo es el de un libro ficticio que presenta la idea subversiva. Así, el lector tiene dos opciones: aceptar ingenuamente la realidad del libro y, por ende, la verosimilitud de la idea, o suspender el descrecimiento en una primera instancia, lo cual potencializa la verosimilitud de la idea presentada como segunda instancia. En otras palabras, la prestidigitación literaria siempre logra crear una ilusión realista cuya mera aceptación confiere a la realidad un carácter ilusorio.

Otras manera de subvertir la realidad consiste en presentar mediante una imagen narrativa un acontecimiento que, de suceder, anularía o al menos cambiaría drásticamente nuestra concepción de lo real. Así, por ejemplo, en PIERRE MENARD, autor del Quijote, se presenta una idea que, si no posible, es al menos concebible: la de repetir o duplicar en forma absolutamente exacta la creación de una determinada obra literaria. En efecto, una característica distintiva de lo real es la de ser irrepetible: repetir la realidad equivale a poder viajar hacia el pasado. Reproducir idénticamente una obra parece más factible que hacer una travesía en el tiempo, pero, ¿es acaso menos invalidadora del orden natural de la realidad? La diferencia del fondo entre una y otra cosa reside únicamente en su grado de verosimilitud.

La idea que se presenta en FUNES EL MEMORIOSO es una variación sobre el mismo tema, solo que en este caso no se repite un acontecimiento real, sino una percepción de la realidad. Lo cual nos remite al viejo "quid" idealista: icuál es la diferencia entre la realidad y la percepción que se tenga de ellas? Para un acontecimiento dado, repetir la totalidad de las percepciones conscientes e inconscientes que se haya tenido de él equivale a volver a percibirlo, lo cual equivale, al menos desde una determinada perspectiva, a volver a repetir ese sector de la realidad. Pero no se crea ahora un autor que repita un libro, sino un hombre capaz de repetir sus percepciones.

Podría alegarse que una sola perspectiva de la realidad no puede constituir testimonio fehaciente: de hecho, el límite entre locura y cordura lo establece un consenso social, i.e., un cotejo de perspectivas individuales. Pero esto puede conducirnos a un absurdo patente: si, como en EL MILAGRO SECRETO, un hecho monstruoso o milagroso fuera objeto de percepción privilegiada, nos veríamos obligados a negar su realidad "eo ipso", o a afirmar la locura de quien lo percibiere. La verdad, pareciera sugerir Borges, es que constantemente confundimos la realidad con nuestra interpretación de ella -en discusión está única- 
mente la validez de las diversas interpretaciones. Así como la realidad puede concebirse equivalente a una interpretación, as 1 la doctrina es equivalente a alguna exágesis, y aquí la costumbre (¿la conveniencia?) suele sustituir al consenso: si el milagro de la Encarnación es ilusorio, su aceptación durante siglos por millones de seres inteligentes constituye una realidad prodigiosa. Por otra parte, si es auténtico, iqué impedimiento racional existe para concebirlo, como Runeberg, acontecido en el cuerpo de Judas Iscariote?

Quizá, en última instancia, "la realidad" no existe sino como subproducto de esa codificación de los preceptos, de esa matriz de acciones que es el lenguaje. La inquietud borgiana tiene plen.t validez, en tanto nos obliga a reexaminar, con rigur y lucidez, los límites que sobre la determinación de nuestro ser establecen ideas y palabras. EI SUR encapsula la fábula última del ciego anciano de Buenos Aires, y quizá no le hubiese parecido menoscabante hacerse eco de los filósofos budistas de la secta Hwa Yen y decir, como ellos, "M= M, M". Juan Dahlmann, por supuesto, hubiera tenido que expresarlo así: "La realidad es su negación. Este hecho es, precisamente, lo que la afirma".

NOTAS

(1) "Haslam ha publicado también $A$ general history of labyrinths". Borges, Jorge Luis. Ficciones, Alianza

(2) Borges, Jorge Luis. Op. Cit., pág. 20. Editorial, Madrid, 1971, pág. 16.

\section{BIBLIOGRAFIA}

BORGES, Jorge Luis. Ficciones, Alianza Editorial, Madrid. 1971.

El informe de Brodie, Emecé Editores, Buenos Aires, 1970.

El Aleph, Emecé Editores, Buenos Aires, 1957.

El libro de Arena, Emecé Editores, Buenos Aires, 1975.

Historia de la eternidad, Alianza Emecé, Madrid, 1981.
Historia universal de la infamia, Alianza Emecé, Madrid, 1981.

POUILLON, Jean y otros. Problemas del estructuralismo, Siglo XXI Editores, 3ra. Edición, México, 1969.

SERRA, Edelweis. Tipología del cuento literario, Cupsa Editorial, Madrid, 1978. 
